\title{
Progressive collapse analysis of a high-rise building considering the effect of an outrigger- belt lateral load resisting system
}

\author{
J. M. Mirhom, H. T. Hafez, K. N. Ibrahim, J. R. Shaker \\ $\&$ M. Abdel-Mooty \\ Department of Construction and Architectural Engineering, \\ The American University in Cairo, Egypt
}

\begin{abstract}
The effect of an outrigger and belt system, mainly provided for resisting lateral wind and seismic loads, on the progressive collapse analysis of a 52 floor high rise building is presented in this paper. The main lateral load resisting element of the building is reinforced concrete core located at the centre of the building. In addition to the RC core walls, two outrigger and belt systems are introduced at the top of the building and at its mid-height. Each system is made of four steel trusses connecting the façade columns to the central reinforced concrete core. Each outrigger system is provided by a belt truss that links all columns on the façade to the outrigger trusses. The purpose of progressive collapse analysis in this paper is to study alternative load paths that eliminates the total collapse and minimizes the local damage and failure of the building. Nonlinear dynamic progressive collapse analysis is carried out where selected columns at the ground level are suddenly removed. This simulates the effect of accidental explosion near the building facade. The nonlinear dynamic analysis is carried out using ELS software (Extreme Loading for Structures) utilizing applied element technique. Different factors that affect the building response to progressive collapse scenarios are studied and presented in this work.
\end{abstract}

Keywords: blast design, progressive collapse, outrigger-belt system, applied element. 


\section{Introduction}

Progressive total collapse of tall buildings is not common event except for the case of controlled demolition. However, after the 9/11 event progressive collapse tall buildings become a major concern when designing tall building. One can learn from the experience of controlled demolition how to protect tall buildings from progressive collapse as a result of terrorist attack or accidental explosion. Bazant and Verdure [1] presented a study of possible mechanism of the WTC progressive collapse and lessons learned from this event. Understanding the load transfer between the different load paths in the event of progressive collapse plays an important role in designing against such event $[2,3]$. Of paramount importance in progressive collapse analysis is the realistic modelling of the various structural elements and connections to reasonably simulate the building's actual behaviour during progressive collapse [4, 5].

This paper addresses the contribution of the outrigger and belt system, mainly provided for resisting lateral wind and seismic loads, in resisting progressive collapse of tall buildings. The outrigger system is a horizontal stiff truss-like structural system that links the outer columns on the building facade to the inner core to enhance the lateral stiffness of the building thus reducing drift under lateral seismic and wind load. As the building deflects under lateral loads, the core slightly bends causing the outrigger to rotate with the core and pull the columns on one side of the building and push the columns on the other side. This creates couple that acts against the lateral load action and reduces lateral drift. In order to increase the efficiency of the outrigger system, a stiff built truss on the building facades at the level of the outrigger is used to make all columns on each façade to work together as one unit. Different location and stiffness of the outrigger and built system are considered in this paper to study alternative load paths that eliminate the total collapse and minimizes the local damage and failure of the building. Nonlinear dynamic progressive collapse analysis is carried out where selected columns at the ground level are suddenly removed. This simulates the effect of accidental explosion near the building facade. The nonlinear dynamic analysis is carried out using ELS software (Extreme Loading for Structures) utilizing an applied element technique. Different factors that affect the building response to progressive collapse scenarios are studied and presented in this work

\section{Building description}

The building considered in this study represents a typical high rise office building consisting of 52 floors, with total floor height $4.2 \mathrm{~m}$. The building has two mechanical floors on the 28th and the 52nd floor. These mechanical floors are double height, $8.4 \mathrm{~m}$ each. The foot-print area of the building is $2436 \mathrm{~m}^{2}$ with overall outer dimensions $47 \times 61 \mathrm{~m}$. 


\subsection{Structural system}

The building plan layout of a typical floor, as shown in Figure 1, is almost symmetrical about two axes with minimal irregularity. Detailed structural analysis and design of the building under gravity load, wind and seismic loads according to the Egyptian design code was carried out. As shown in the figure below, 2 facades have 6 exterior columns while the other 2 facades have 7 columns. A Concrete Core is placed in the centre of the building to resist the lateral load subjected to the tall building. On the 28th and 52nd floors, an outrigger system is used to help resist the lateral loads both (seismic and wind). The design of the building will be briefly explained as follows: slabs, beams, columns, core, outrigger system, and the foundation system.

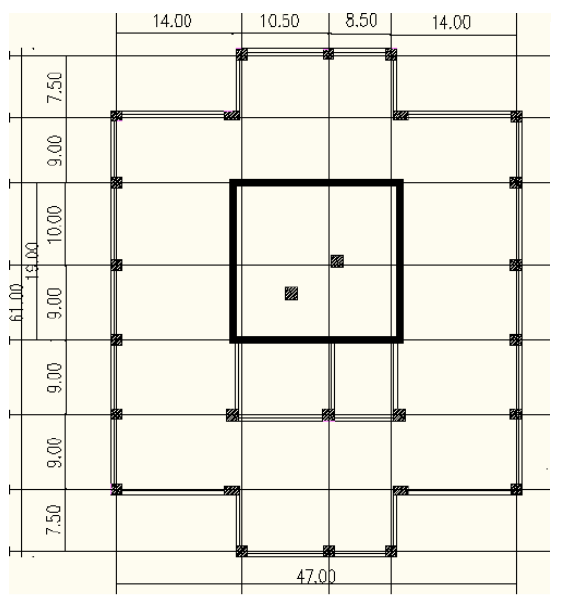

a) Floor plan

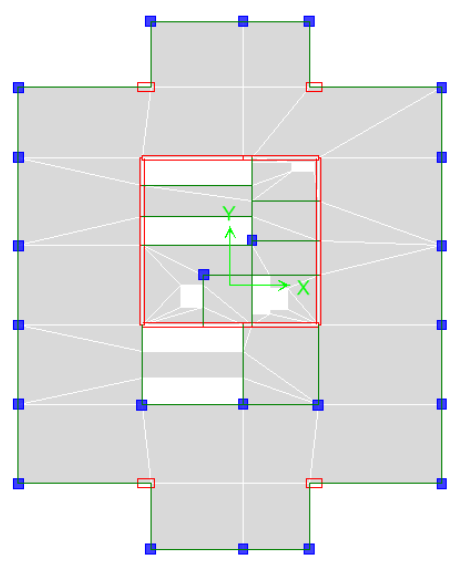

b) floor model

Figure 1: Plan layout showing dimensions and structural system of a typical floor.

Due to the large spans in the order of 9 to $14 \mathrm{~m}$, post-tensioned prestressed slab of thickness $300 \mathrm{~mm}$ supported on marginal beams of cross-section $400 \times 1250 \mathrm{~mm}$ are used for the typical floor as shown in Fig. 1. Limited number of inner reinforced concrete beams of cross section 250x1000 mm is used in order to reduce deflection at location of large spans and heavy loads, as shown in Fig. 1. Prestressing Case D, as per the Egyptian code was used for the slab design which allows for partial prestressing. Ten different cable profiles are used in the slab, 6 in the $\mathrm{X}$ (short) direction, and 4 in the $\mathrm{Y}$ (long) direction. The typical cable spacing is $750 \mathrm{~mm}$ in X-direction and $1000 \mathrm{~mm}$ in Y-direction. Bottom reinforcement mesh consisting of $10 \mathrm{~mm}$ steel bar every $100 \mathrm{~mm}$ in both directions and top reinforcement mesh consisting of $8 \mathrm{~mm}$ steel bar every $100 \mathrm{~mm}$ in both directions are used as main reinforcement. Additional localized reinforcement is added where applied bending moment exceeds the moment resistance of the main reinforcement mesh. 
Three different alternatives for column design are used in this building: reinforced concrete sections in all floors; steel-RC composite sections in all floors; and composite sections up till the 28th floor then reinforced concrete columns till the 52nd floor.

The central reinforced concrete core was design under combined axial gravity load and bending moment due to lateral seismic and wind loads. Using the CSI columns software as used for the columns, the core system was designed to be a reinforced concrete section with 0.8 meters thickness for the first ten floors and then reduction of $5 \mathrm{~cm}$ every five floors up to the 52nd floor. The software used assured that the core can handle the lateral loads of the building safely and economically.

\subsection{Outrigger and built system}

The building is provided with two outrigger and belt truss systems at the 28th floor and the 52nd floor. The main purpose of using outrigger system is to decrease the lateral drift under wind and seismic load. The outrigger and built truss system increases the overall lateral stiffness of the building through coupling the outer columns with the central core which reduces the overall lateral bending deformation of the building under wind and seismic loads. An outrigger works best in places with maximum rotation and drift. Thus, trying to reach the efficiency of the outrigger system in resisting blast loads, the outrigger system is composed of 2 main elements: the outrigger and the belt. The function of the built is to make all columns on the façade work together as one system. Figure 2 shows the plan layout of the outrigger-built-system. The structural system of the outrigger and the built is open truss system extended over double story height assigned to the mechanical floors at the 28th and 52nd floors, as shown in Figure 3. The members of the outrigger truss are a hollow steel box section 1250x1250 $\mathrm{mm}$ and wall thickness $40 \mathrm{~mm}$.

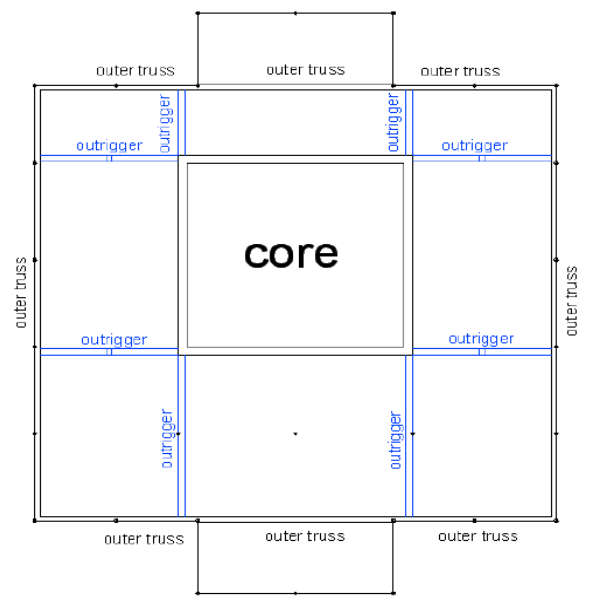

Figure 2: Plan layout of the outrigger and built system. 


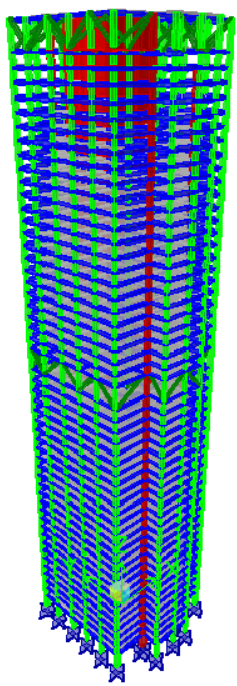

a) building model

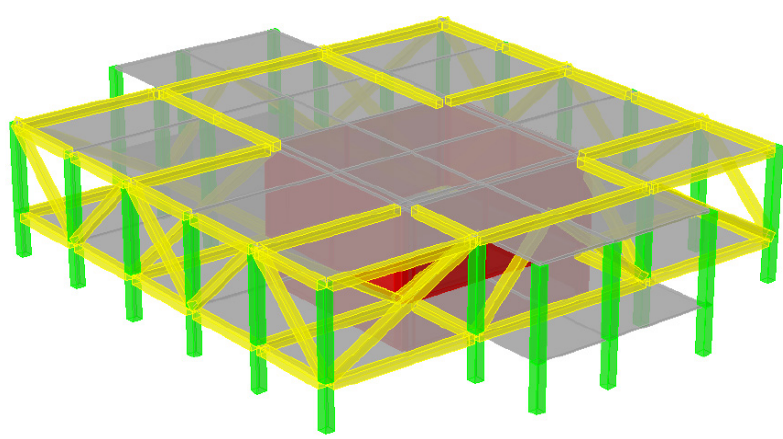

b) outrigger and built system close-up

Figure 3: The outrigger and built truss system.

\section{Progressive collapse analysis}

To study the propagation of failure in a building in a progressive collapse scenario, it is necessary to carry out extensive structural analysis to study the forces exerted on every member affected by the impact and initial failures. This requires the analysis of the forces, and the material behaviour with time. As the members approach failure, the stresses exceed the yield point, and material deformation becomes nonlinear. Therefore the most accurate analysis would have to be both nonlinear and dynamic which is iterative and lengthy process.

Several researchers and have carried out extensive research in the field to simplify the analysis methods and reduce them to simple linear and static methods creating guidelines with conservative acceptance criteria [4]. However these methods are not always applicable, and can only be used if the following conditions apply to the building.

- The building is around ten floors tall.

- The building has a simple and symmetric structural system where alternative load paths are clear.

- Lack of special structures, such as trusses, which distorts the load redistribution in case of local failure.

As could be easily concluded based on the structure description above, these limitations are breached in the considered building and therefore full dynamic nonlinear analysis is required.

Nonlinear dynamic analysis for progressive collapse is carried out in this study using commercial software ELS (Extreme loading for structure) [6]. The ELS software is based on the applied element method (AEM) unlike most of the 
available software used in the design of the building that is based on finite element method (FEM). The AEM differs from the commonly used FEM for structural analysis and design in many aspects. First the elements are connected together using surface springs and not necessarily at nodes as used in FEM. Second, springs model structural behaviour even after separation. Third there is no transition needed between large and small elements. Details of the used software can be found in [6], while the figure below shows the difference in connectivity between the FEM and AEM.

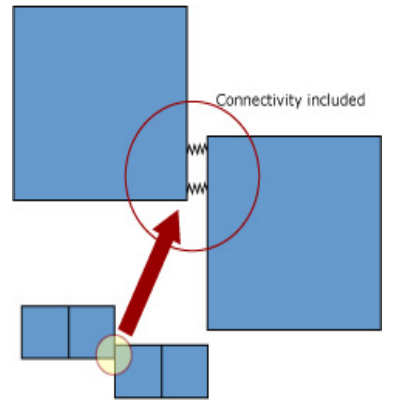

Applied Element Method

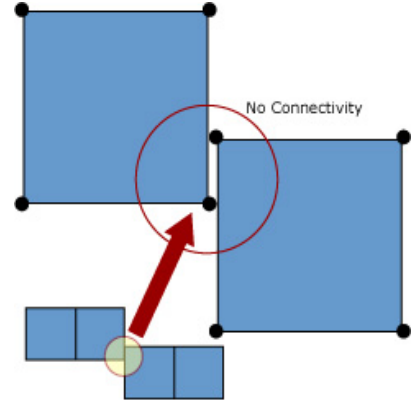

Finite Element Method

Figure 4: Difference in element connectivity in FEM and AEM [6].

\section{Progressive collapse study cases}

Progressive collapse is initiated by sudden failure of a limited number of critical members, usually columns, due to a blast scenario that later on triggers the failure of the whole building. The first step would be to determine the blast scenario on the proposed structure, then analyze the direct damage that results from this blast, then predict the failure that will progress throughout the building. Three different scenarios of failure are considered in this paper, two in the northern façade and one in the western façade. Since the building's architecture is symmetrical, it is apparent that those trials are comprehensive.

First, using ELS, the analysis program that was explained earlier, a model representing the structural system of the building, but without the outrigger system, was built using the ELS software. Then the blast mode of failure was simulated as removal of some columns at the ground floor that would be susceptible to blast load. In the first mode that is shown in Figure 5-a, it is assumed that the blast load will be enough to remove fully 5 columns in the northern façade in the first two floors. After simulating the failure on ELS, the program ran an analysis scheme for 2 processing days that result in the failure mode shown in the Figure 6. The figure shows several shots of the simulation of the failure without the outrigger. The results of nonlinear dynamic analysis, as shown in Fig. 6, indicates that the whole building collapses. It is concluded that without the outrigger system, the percentage loss of concrete volume due to the selected blast scenario is $100 \%$. 


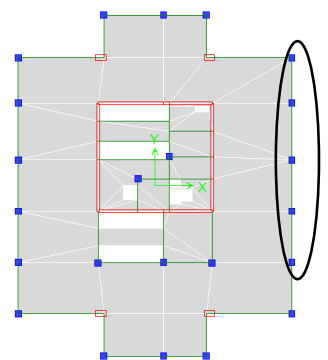

a) 5 columns northern side

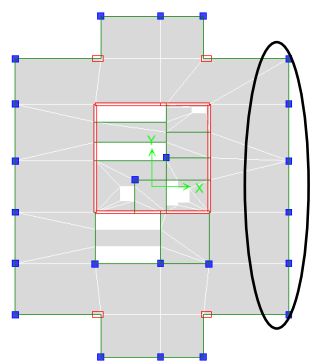

b) 6 columns northern side

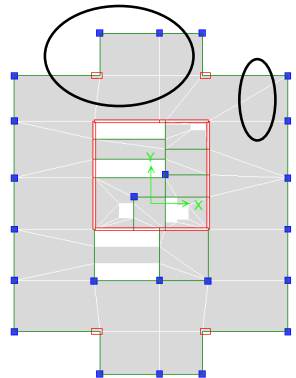

c) 7 columns western side

Figure 5: Different scenarios for columns failure at ground floor due to blast.
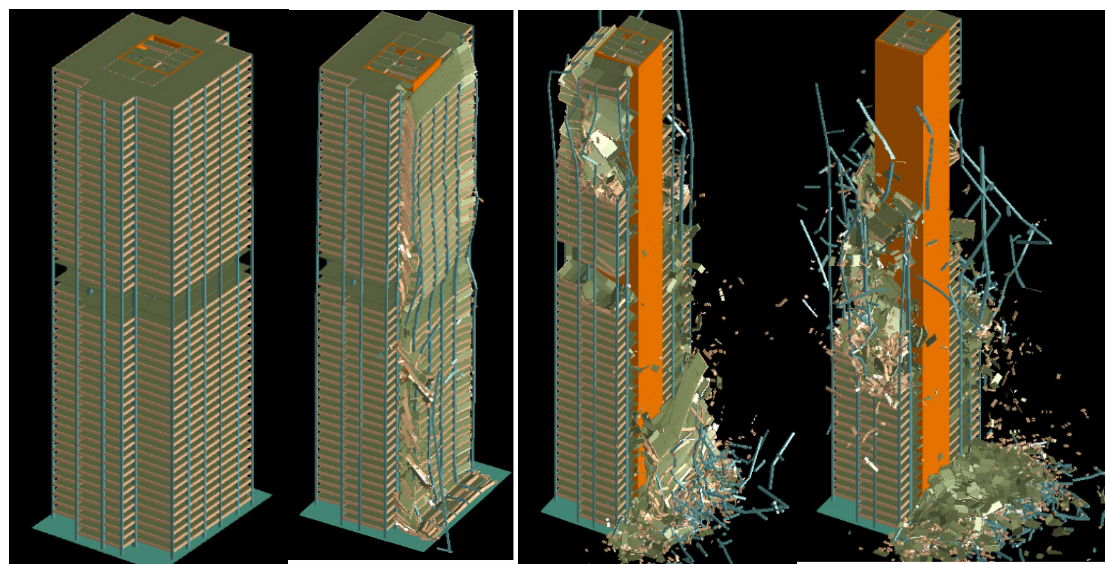

Figure 6: Progressive collapse of tall building without outrigger-built system due to removing 5 columns on the northern façade.

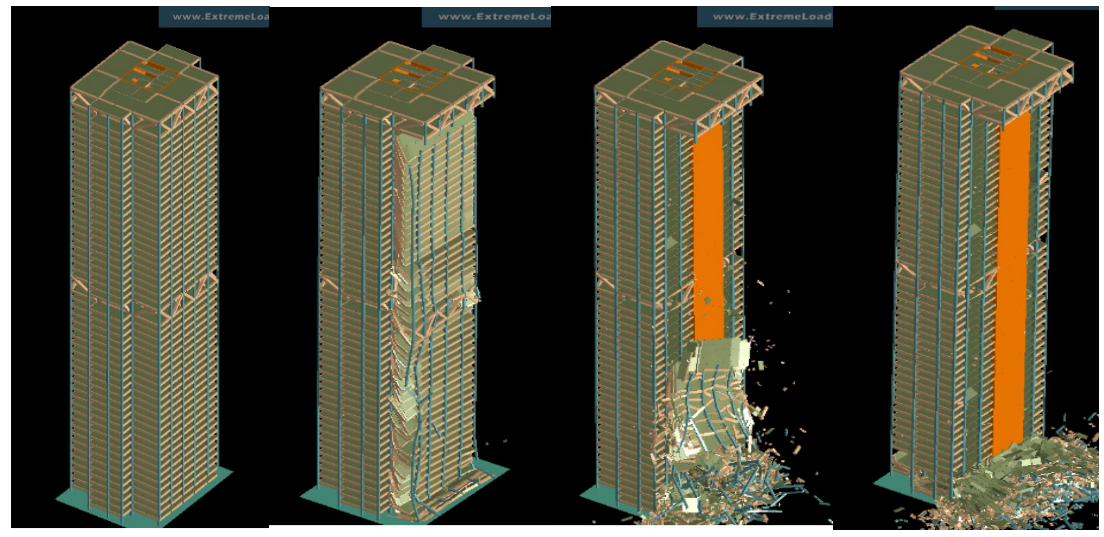

Figure 7: Progressive collapse of tall building with outrigger-built system due to removing 5 columns on the northern façade. 
The same procedure was then repeated with the existence of the outrigger system. It is important though to state that the outrigger system was developed in the first place to overcome the lateral loads and to satisfy the drift requirements of the modal analysis, but the building is statically safe without it. Figure 7 shows the simulation of the failure with the outrigger system.

The difference between the failure mode for building with and without the outrigger and built system is evident. That is because the northern façade where the 5 columns were destroyed in the first 2 floors is the only façade affected and the outrigger system prevented the failure from extending to the other elements of the building reducing the percentage loss of concrete to only about $30 \%$.

The second trial was on the same façade but with 6 columns removed from the northern façade instead of 5, in order to see to what extent can the outrigger system help the building in limiting the progressive collapse. Of course to make the experiment subjective, the same blast scenario was assumed in this trial and thus these 6 were removed from the first 2 floors only of the northern façade. The result of this case of removing 6 columns was almost the same as the first scenario of removing 5 columns for both with and without outrigger. This shows the effect of the outrigger system in preventing the progressive collapse of the whole building not only when 5 columns are removed, but also when all the columns in the façade in the first 2 floors are removed.

The third scenario is the sudden removal of seven columns on the western façade and the corner in the ground and first floor due to blast. Figure 8 shows the model response for the case without outrigger-built system in the 28th and the 52nd floor. The snapshots shown in Figure 8 show that the structure exhibits total failure due to the progressive collapse concept similar to the failure that occurred upon running the other two modes without having the outrigger system.
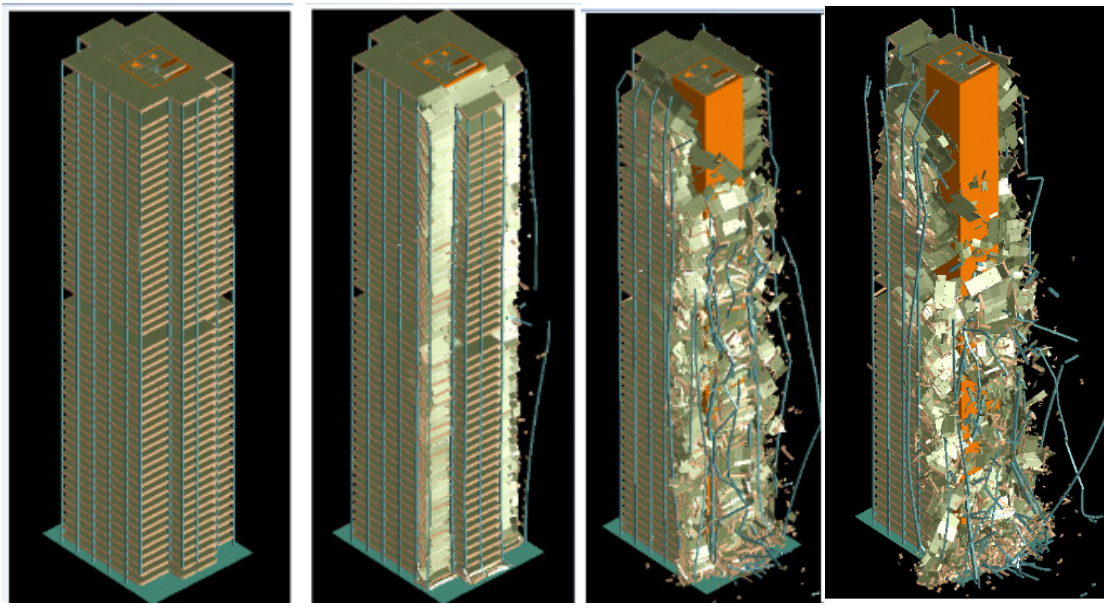

Figure 8: $\quad$ Progressive collapse of tall building without outrigger-built system due to removing 7 columns on the western façade. 
After adding the outrigger system that was primarily designed to satisfy the drift requirements, and although this scenario includes the removal of 7 critical columns as shown, the building fully succeeded to resist the blast event that removed 7 columns with local damage limited to only the slabs and beams of the first two floors of the affected facades as shown in Figure 9. This shows that the outrigger system indeed adds to the redundancy of the building and its ability to resist progressive collapse.
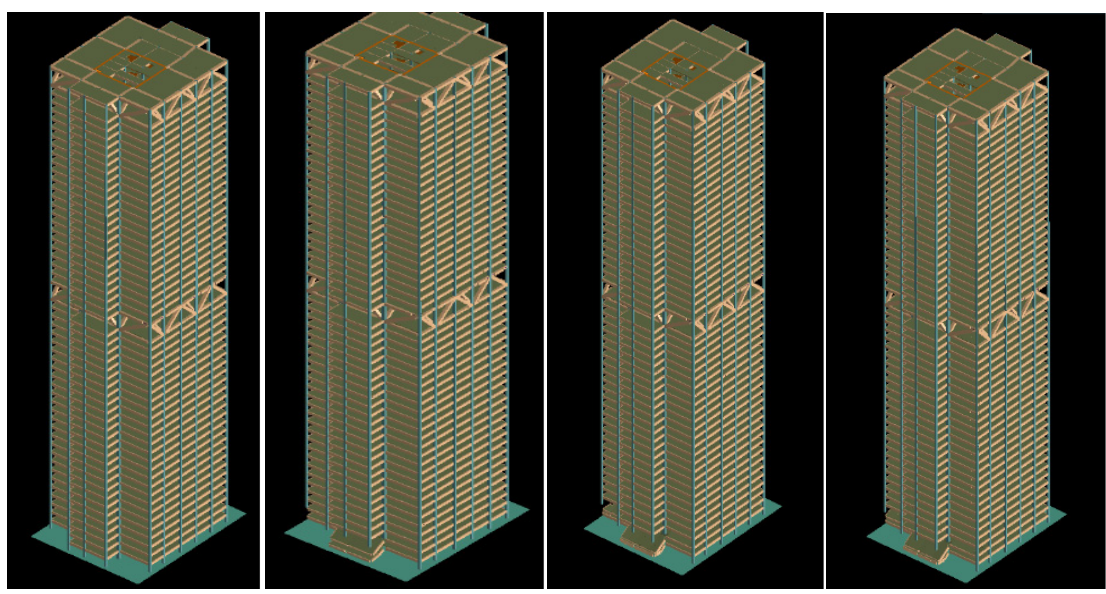

Figure 9: Progressive collapse of tall building with outrigger-built system due to removing 3 columns on the western façade.

\section{Conclusion}

Nonlinear dynamic progressive collapse analysis of tall building is considered in this paper. A 52 story high office building is considered with and without outrigger-built system. The building is proportioned to withstand the lateral wind and seismic load without the outrigger which is added to enhance its stiffness and reduce lateral drift. The nonlinear analysis is carried out utilizing the applied element method (AEM) and using commercially available software Extreme Loadings for Structures (ELS).

The blast effect is simulated by the sudden removal of some columns at selected locations in the ground and first floor. Three different scenarios are considered for blast event. The building was analyzed for the different scenarios for progressive callable. It is shown that the use of outrigger and built system adds to different load baths to the building that contributes to its resistance to progressive collapse. While the model without outrigger system went through full failure and $100 \%$ damage, the case with outrigger system was able to resist the blast event with minimum local damage. It is concluded that a well proportioned outrigger and built system can prevent progressive collapse, protect properties and save lives. 


\section{References}

[1] Bazant, Z., and Verdure, M., Mechanics of Progressive Collapse: Learning from World Trade Center and Building Demolitions, Journal of Engineering Mechanics, ASCE, 133(3), pp. 308-319, 2007.

[2] Loizeaux, M., Osborn A., Progressive Collapse-An Implosion Contractor's Stock in Trade. Journal of Performance of Constructed Facilities, ASCE, 20(4), 391-402, 2006.

[3] Sasani, M., Kazemi, A, Sagiroglu, S., and Forest S., Progressive collapse resistance of an actual 11-story structure subjected to severe initial damage, Journal of Structural Engineering, ASCE, 137(9), pp. 893-902, 2011.

[4] Alashker, Y., Li, H., and El-Tawil, S., Approximations in Progressive Collapse Modeling. Journal of Structural Engineering, ASCE, 137(9), pp. 914-924, 2011.

[5] Kanno, Y. and Ben-Haim, Y., Redundancy and robustness, or when is redundancy redundant? Journal of Structural Engineering, ASCE, 137(9), pp. 935-945, 2011.

[6] Extreme Loading for structures. Applied Science International. 2009. http://www.extremeloading.com/ 